Journal of Healthcare Technology and Medicine Vol. 3 No. 2 Oktober 2017

Universitas Ubudiyah Indonesia

e-ISSN : 2615-109X

\title{
HUBUNGAN PENGETAHUAN DAN PENDAPATAN DENGAN \\ STATUS GIZI PADA BALITA DI WILAYAH KEJA PUSKESMAS DELIMA KABUPATEN PIDIE
}

\author{
Relationship Of Knowledge And Income With Nutritional Status In Children In The \\ Working Area Puskesmas Delima Pidie District \\ Zulfahmi*1, Rauzah Tunnur $^{2}$ \\ Koresponding email : zulfahmi@uui.ac.id*1, rauzah.t@gmail.com² \\ Universitas Ubudiyah Indonesia
}

\begin{abstract}
Abstrak
Gizi adalah suatu proses organisme menggunakan makanan yang dikonsumsi secara normal melalui proses pencernaan, penyerapan, transportasi, penyimpanan, metabolisme dan zat gizi untuk mempertahankan kehidupan, pertumbuhan dan fungsi normal organ tubuh untuk menghasilkan tenaga (Djoko, 2006). Di Puskesmas Delima Kabupaten Pidie diperoleh permasalahan Hubungan Pengetuan Dan Pendapatan Dengan Status Gizi Pada Balita, yaitu dari 15 ibu didapatkan 5 ibu (33,3\%) yang tidak mengerti tentang status gizi, karena tamatan SD dan tidak pernah menanyakan pada petugas kesehatan (bidan), dan dari 15 ibu didapatkan 8 ibu $(53,5 \%)$ yang pendapatanya kurang dari Rp 1350.000,- perbulan. Penelitian ini bertujuan untuk mengetahui Hubungan Pengetahun Dan Pendapatan Dengan Status Gizi Pada Balita di wilayah kerja Puskesmas Delima Kabupaten Pidie. ini bersifat analitik dengan desain Cross secsional, yang dilakukan di wilayah Puskesmas Delima pada tanggal 22 sampai dengan 26 juli 2015 dengan jumlah populasi 696 ibu yang mempunyai balita dan menggunakan teknik pengambilan random sampling sehingga diperoleh sampel 88 responden. Analisa data menggunakan metode univariat dan bivariat yaitu dengan melihat presentase data yang terkumpul dan disajikan dalam bentuk tabel distribusi frekuensi dan juga menggunakan teori keputakaan yang ada. dari 88 responden terdapat status gizi baik yaitu 59 responden $(67,1 \%), 46$ responden $(53,4 \%)$ pengetahuan sedang, dan 59 responden $(67,1 \%)$ diantaranya pendapatan tinggi. Berdasarkan uji chi-square dengan menggunakan bantuan program SPSS bahwa ada hubungan antara pengetahuan dengan status gizi balita yaitu (p-Value $=0,005<0,05)$ dan ada hubungan antara pendapatan dengan status gizi balita yaitu ( $\mathrm{p}$-Value $=0,010<0,05$ ). Kepada petugas Puskesmas Delima khususnya bagian gizi agar dapat meningkatkan penyuluhan sehingga dapat meningkatkan pengetahuan masyarakat tentang kebutuhan gizi pada baita dan dapat memberikan informasi kepada ibu- ibu yang memiliki balita agar dalam penyajian makanan untuk lebih memperoritaskan balita.
\end{abstract}

\section{Kata Kunci: Status Gizi Pada Balita, Pengetahuan, Pendapatan}

\begin{abstract}
Nutrition is a process of organisms using food that is consumed normally through the process of digestion, absorption, transportation, storage, metabolism and nutrients to maintain life, growth and normal function of the body's organs to produce energy (Djoko, 2006). In the Delima Health Center in Pidie District, the problems of Tapping and Income Relationship with Nutritional Status in Toddlers, from 15 mothers found 5 mothers (33.3\%) who did not understand the nutritional status, because they graduated from elementary school and never asked the health worker (midwife), and from 15 mothers, there were 8 mothers (53.5\%) whose income was less than Rp. 1,350,000 per month. This study aims to determine the Relationship between Knowledge and
\end{abstract}


Journal of Healthcare Technology and Medicine Vol. 3 No. 2 Oktober 2017

Universitas Ubudiyah Indonesia

e-ISSN : 2615-109X

Income and Nutritional Status of Toddlers in the work area of the Delid Puskesmas in Pidie Regency. This is an analytic cross-sectional design, which was carried out in the Delima Puskesmas area on 22 to 26 July 2015 with a population of 696 mothers who have children under five and using random sampling techniques to obtain a sample of 88 respondents. Data analysis uses univariate and bivariate methods by looking at the percentage of data collected and presented in the form of frequency distribution tables and also using existing theory theory. of 88 respondents there is good nutritional status, namely 59 respondents (67.1\%), 46 respondents (53.4\%) of moderate knowledge, and 59 respondents (67.1\%) of whom have high income. Based on the chisquare test using the help of SPSS program that there is a relationship between knowledge and nutritional status of children under five years $(p$-Value $=0.005<0.05)$ and there is a relationship between income and nutritional status of children under five years old ( $p$-Value $=0.010<0,05)$. To the Delima Health Center staff especially the nutrition department in order to increase counseling so as to increase community knowledge about nutritional needs in babies and to provide information to mothers who have children under five so that in serving food to prioritize toddlers.

\section{Keywords: Nutrition Status in Toddlers, Knowledge, Income}

\section{PENDAHULUAN}

Gizi adalah suatu proses organisme menggunakan makanan yang dikonsumsi secara normal melalui proses pencernaan, penyerapan, transportasi, penyimpanan, metabolisme dan zat gizi untuk mempertahankan kehidupan, pertumbuhan dan fungsi normal organ tubuh untuk menghasilkan tenaga (Djoko, 2006).

Angka kematian balita (AKABA) adalah jumlah kematian anak umur $0-<5$ tahun per 1000 kelahiran hidup. AKABA menggambarkan tingkat permasalahan kesehatan anak dan faktor-faktor lain yang berpengaruh terhadap kesehatan anak balita seperti gizi. Hasil SDKI 2002-2003 angka kematian balita 64 per 1000 kelahiran hidup, belum mencapai target 58 per 1000 kelahiran hidup (Dinkes, 2005)

Berbagai faktor yang mempengaruhi status gizi pada balita antara lain kurangnya persediaan pangan, kurang baiknya kualitas lingkungan (Almitsier S, 2001). Adapun faktor lain yang mempengaruhi adalah kondisi sosial ekonomi dan budaya keluarga seperti pola asuh keluarga (Depkes RI, 2002). Berdasarkan study pendahuluan dari 15 ibu di wilayah kerja Puskesmas Delima didapatkan hanya 5 ibu yang tidak mengerti tentang status gizi, karena lulusan SD dan tidak pernah menanyakan pada petugas kesehatan (bidan), dan dari $15 \mathrm{ibu}$ hanya 8 ibu yang pendapatanya kurang dari Rp 1350.000 ,perbulan. 
Journal of Healthcare Technology and Medicine Vol. 3 No. 2 Oktober 2017

Universitas Ubudiyah Indonesia

e-ISSN : 2615-109X

\section{METODE PENELITIAN}

Penelitian ini bersifat analitik dengan desain Cross secsional yaitu untuk mengetahui Hubungan Pengetahuan dan Pendapatan Dengan status gizi pada balita di Wilayah kerja Puskesmas Delima Kabupaten Pidie Populasi yang digunakan dalam penelitian ini adalah seluruh ibu yang memiliki balita yang pernah berkunjung dari bulan September sampai dengan November ke Puskesmas Delima berjumlah 696 orang.

\section{HASIL DAN PEMBAHASAN}

\section{Hubungan Antara Pengetahuan Dengan Status Gizi Balita}

\section{Tabel 1}

Hubungan Antara Pengetahuan Dengan Status gizi Balita Di Puskesmas Delima Kabupaten Pidie Tahun 2015

\begin{tabular}{|c|c|c|c|c|c|c|c|c|}
\hline \multirow{3}{*}{ No } & \multirow{3}{*}{ Pengetahuan } & \multicolumn{4}{|c|}{ Status Gizi } & \multirow{3}{*}{$\mathbf{F}$} & \multirow{3}{*}{$\%$} & \multirow{3}{*}{ P-value } \\
\hline & & \multicolumn{2}{|c|}{ Baik } & \multicolumn{2}{|c|}{ Kurang } & & & \\
\hline & & $\mathbf{F}$ & $\%$ & $\mathbf{F}$ & $\%$ & & & \\
\hline 1 & Tinggi & 10 & 62,5 & 6 & 37,5 & 16 & 100 & \multirow{4}{*}{0,005} \\
\hline 2 & Sedang & 38 & 82,6 & 8 & 17,3 & 46 & 100 & \\
\hline 3 & Rendah & 11 & 42,3 & 15 & 57,7 & 26 & 100 & \\
\hline & Total & & & & & & & \\
\hline
\end{tabular}

Berdasarkan tabel 1 diketahui bahwa dari 46 reponden pengetahuan sedang, 38 responden $(82,6 \%)$ status gizi baik. Berdasarkan uji chi-square dengan menggunakan bantuan program SPSS bahwa ada hubungan antara pengetahuan dengan status gizi balita yaitu $(\mathrm{p}-$ Value $=0,005<0,05)$.

Penelitian ini sejalan dengan Suhardjo (2003) yang menyebutkan bahwa kurangnya pengetahuan dan salah konsepsi tentang kebutuhan pangan dan nilai pangan adalah umum dijumpai setiap Negara di dunia. Kemiskinan dan kekurangan persediaan pangan yang bergizi merupakan faktor penting dalam masalah kurang gizi.

Di banyak daerah, pangan yang bergizi tidak diberikan kepada anak-anak kaena khawatir adanya akibat yang merugikan. Di bagian tertentu di Negara Indonesia, ikan dilarang bagi anak-anak karena adanya kepercayaan bahwa ikan menyebabkan penyakit cacingan, gangguan mata, dan penyakit kulit. Hal ini disebabkan karena kurangnya pengetauan masyarakat (Linda, 2005). 
Journal of Healthcare Technology and Medicine Vol. 3 No. 2 Oktober 2017

Universitas Ubudiyah Indonesia

e-ISSN : 2615-109X

Berdasarkan data hasil analisa statistik yang dikemukakan di atas, dapat diasumsikan penyediaan makanan sehat padabalita dipengaruhi oleh pengetahuan ibu. Semakin baik pengetahuan ibu, maka ibu memiliki kecenderungan untuk memahami akan pentingnya status gizi untuk pertumbuhan dan perkembangan balita.

Pengetahuan yang baik tidak menjamin ibu dapat memenuhi gizibalitanya. Hal ini disebabkan karena pengetahuan ibu yang baik tidak didukung dengan pendapatan keluarga dan tradisi atau kebiasaan membuat ibu tidak dapat memenuhi gizi balitanya.

\section{Hubungan Antara Pendapatan dengan Status Gizi Balita}

Tabel 2

\section{Hubungan Antara Pendapatan Dengan Status Gizi Balita} Dipuskesmas Delima Kabupaten Pidie

\begin{tabular}{|c|c|c|c|c|c|c|c|c|}
\hline \multirow{3}{*}{ No } & \multirow{3}{*}{ Pendapatan } & \multicolumn{4}{|c|}{ Status Gizi } & \multirow{3}{*}{$\mathbf{F}$} & \multirow{3}{*}{$\%$} & \multirow{3}{*}{ P-value } \\
\hline & & \multicolumn{2}{|c|}{ Baik } & \multicolumn{2}{|c|}{ Kurang } & & & \\
\hline & & $\mathbf{F}$ & $\%$ & $\mathbf{F}$ & $\%$ & & & \\
\hline 1 & Tinggi & 46 & 77,9 & 13 & 22,1 & 59 & 100 & \\
\hline 2 & Rendah & 13 & 44,8 & 16 & 55,2 & 29 & 100 & 0,010 \\
\hline & Total & & & & & & & \\
\hline
\end{tabular}

Berdasarkan tabel 2 diketahui bahwa dari 59 responden pendapatan tinggi dimana 46 responen $(77,9 \%)$ diantaranya status gizi baik. Berdasarkan uji chi-square dengan menggunakan bantuan program SPSS bahwa ada hubungan antara pendapatan dengan status gizi balita yaitu ( $\mathrm{p}$-Value $=0,010<0,05)$.

Penelitian ini sejalan dengan pendapat yang di kemuakan oleh Linda (2005) dimana tingkat penghasilan akan mempengaruhi pemilihan terhadap bahan makanan apa yang akan di beli. Jadi penghasilan merupakan factor penting bagi kwantitas dan kualitas makanan. Antara penghasilan dan gizi, jelas ada hubungannya. Pengaruh peningkatan penghasilan terhadap perbaikan kesehatan dan kondisi keluarga yang mengadakan interaksi dengan status gizi yang berlaku hampir universal. Dari hasil penelitian di dapat adanya kecendrungan hubungan antara tingkat pendapatan keluarga dengan status gizi anak balita.

Berdasarkan data hasil analisa statistik yang dikemukakan di atas, dapat diasumsikan bahwa pendapatan keluarga berhubungan dengan status gizi balita. Keluarga yang berpendapatan rendah biasanya mempunyai status gizi buruk. Hal ini disebabkan karena 
Journal of Healthcare Technology and Medicine Vol. 3 No. 2 Oktober 2017

Universitas Ubudiyah Indonesia

e-ISSN : 2615-109X

ketidakmampuan untuk memenuhi kebutuhan makanan yang bergizi seimbang. Keluarga yang berpendapatan rendah pada umumnya tidak memperhatikan masalah asupan gizi, yang terpenting anaknya dapat makan walaupun tidak memenuhi kriteria makanan sehat.

Pendapatan keluarga yang tinggi belum tentu dapat memenuhi gizi pada balita. Hal ini disebabkan karena kurangnya pengetahuan ibu terhadap status gizi. Pendapatan keluarga yang rendah bukan hambatan bagi ibu untuk menyediakan makanan sehat, karena makanan sehat tidak harus makanan yang harganya mahal tetapi dapat memenuhi kebutuhan gizi seimbang.

\section{KESIMPULAN}

Berdasarkan hasil penelitian yang telah dilakukan tentang Hubungan Pengetahuan Dan Pendapatan Dengan Status Gizi Pada Balita di wilayah kerja Puskesmas Delima Kabupaten Pidie dengan 88 responden maka dapat disimpulkan sebagai berikut.

1. Ada hubungan antara pengetahuan dengan status gizi pada balita di wilayah kerja Puskesmas Delima Kabupaten Pidie.

2. Ada hubungan antara pendapatan dengan status gizi pada balita di wilayah kerja Puskesmas Delima Kabupaten Pidie.

\section{DAFTAR PUSTAKA}

Djoko. 2006. Indikator Statistik Vital Kependudukan Dan Kesehatan. Surabaya, CV. Duta Prima Airlangga..

Dinkes, Prov. NAD. 2006. Profil Kesehatan NAD 2006, Banda Aceh.

Depkes RI. 2012.Pengelolaan Program Perbaikan Gizi. Jakarta.

Almatsier, S, Pinsip Dasar Ilmu Gizi. Gramedia Pustaka Utama, Jakarta, Notoatmodjo. 2005. Ilmu Kesehatan Masyarakat. Jakarta, Rineka Cipta. Suhardjo. 2005. Perencanaan Pangan dan Gizi. Jakarta, Bumi Aksara 